\title{
Effect of COVID-19 lockdown on noise pollution levels in an Indian city: a case study of Kanpur
}

\author{
Anirudh Mishra $^{1} \cdot$ Sanhita Das ${ }^{2} \cdot$ Deepesh Singh $^{1} \cdot$ Akhilesh Kumar Maurya $^{3}$ \\ Received: 9 February 2021 / Accepted: 6 April 2021 / Published online: 22 April 2021 \\ (C) The Author(s), under exclusive licence to Springer-Verlag GmbH Germany, part of Springer Nature 2021
}

\begin{abstract}
Noise pollution is an emerging environmental threat, prolonged exposure of which can cause annoyance, sleep disturbance, hypertension, psychiatric disorders, and also hormonal dysfunction. Among all the sources of noise pollution, the noise generated by road vehicle traffic significantly affects the quality of urban environments. Concerning the recent imposition of COVID-19 societal lockdown, this study attempts to investigate the impacts of COVID-19 lockdown on the changes in noise pollution levels before, during, and after lockdown phase in different residential, commercial, industrial, and silence zones of the city of Kanpur, India. Utilizing data collected from portable environmental sensors, the average noise levels before lockdown and during lockdown were found to be in the range of $44.85 \mathrm{~dB}$ to $79.57 \mathrm{~dB}$ and $38.55 \mathrm{~dB}$ to $57.79 \mathrm{~dB}$, respectively, for different zones. Although a significant reduction in the noise levels was observed during lockdown, except for commercial zone, all other monitoring stations had reported sound levels quite higher than the recommended noise limits set by the Central Pollution Control Board (CPCB) of India. Results further indicated that the impact of road traffic noise on risk of high annoyance and sleep disturbance was found to be lower during lockdown as compared to that of pre-lockdown and unlock phase. While the annoyance level in residential (86.23\%), industrial (87.44\%), and silence (84.47\%) was higher in pre-lockdown period, it reduced to $41.25,50.28$, and $43.07 \%$ in the lockdown phase. Even the risk of sleep disturbance in the residential zone was found to reduce from $37.96 \%$ during pre-lockdown to $14.72 \%$ during lockdown phase. Several noise mitigation strategies are also proposed, which may indeed pave the way for devising noise control measures in the local and regional level.
\end{abstract}

Keywords COVID-19 $\cdot$ Noise pollution $\cdot$ Residential $\cdot$ Silence $\cdot$ India

\section{Introduction}

Noise caused by increased urbanization and industrialization is recognized as environmental nuisance that affects human health and well-being (Mansouri et al. 2006). The World Health Organization (WHO) has reported noise pollution as one of the major environmental contributors to public health

Responsible Editor: Philipp Gariguess

Sanhita Das

sanhi.das25@gmail.com

1 Department of Civil Engineering, Harcourt Butler Technical University, Kanpur 208002, India

2 Department of Civil Engineering, Indian Institute of Technology Roorkee, Roorkee, Uttarakhand 247667, India

3 Department of Civil Engineering, Indian Institute of Technology Guwahati, Guwahati, Assam 781039, India challenges (WHO 2018). Among all the sources of noise pollution, the noise generated by road vehicle traffic significantly affects the quality of urban environments (Méline et al. 2013; Paiva et al. 2019; Amoatey et al. 2020). It is recognized that increased exposure to noise can cause annoyance (Dratva et al. 2010; Babisch 2002; Stansfeld and Matheson 2003), sleep disturbance involving frequent awakening (Muzet 2007; Guski et al. 2017), hormonal dysfunction (Said and El-Gohary 2016), hypertension (Eriksson et al. 2012; Fuks et al. 2017; Oh et al. 2019), and also psychiatric disorders (Fyhri and Aasvang 2010; Ongel and Sezgin 2016).

Depending on the duration, intensity of noise, and distance from noise source, the effects of noise on human health and comfort can be essentially divided into four groups: physical effects such as hearing and ear burning; physiological effects, such as increased blood pressure, irregularity of heart rhythms, and ulcers; psychological effects, such as disorders, irritability, annoyance, and stress; and finally performance effects, such as reduction of productivity and lack of 
concentration (Yilmaz and Ozer 2005; Saadu et al. 1998; Tekalan 1991; Singh and Davar 2004; Okah-Avae 1996). In essence, the impact of noise pollution on public health outcomes has been a major concern worldwide (Abo-Qudais and Alhiary 2004; Bhadram 2003; Georgiadou et al. 2004).

Concerning increased exposure to noise pollution in Indian cities, recent literature has underlined that the average noise level in different cities often exceeds the limits recommended by the Central Pollution and Control Board of India (Bhosale et al. 2010; Banerjee et al. 2008; Sagar and Rao 2006; Kisku et al. 2006; Jamir et al. 2014). A study by Banerjee et al. (2008) reported that the maximum day time and night time noise equivalent level in an industrial town of West Bengal exceeded the recommended noise limit by $14 \mathrm{~dB}$ and $11.9 \mathrm{~dB}$, respectively. Kisku et al. (2006) indicated that the maximum equivalent noise levels exceed by 23.9 and $11.4 \mathrm{~dB}$ in residential areas of the city of Lucknow during day and night times, respectively, by 19.2 and $19.9 \mathrm{~dB}$ in commercial cum traffic areas and by 2.2 and $3.1 \mathrm{~dB}$ in industrial areas. Thakre et al. (2020) further found an increment by $4.4 \mathrm{~dB}$ and $5.2 \mathrm{~dB}$ for morning and evening sessions, respectively, in the city of Nagpur from the year 2012 to 2019. In a recent study conducted in residential, commercial, industrial, and silence zones of Mumbai Metropolitan Region, Kalawapudi et al. (2020) reported that silence zones were mostly affected by noise pollution, followed by residential, commercial, and industrial zones. They further concluded that appropriate planning of city spaces could avoid exposure to rising noise pollution levels.

The emerging evidence suggests that most of the Indian cities are under potential threat of increased noise exposure that can have deleterious effects on the physical and mental health of individuals. Howbeit, the recent imposition of COVID-19 societal lockdown has substantially reduced vehicular traffic volume and social events worldwide. In an attempt to delve deeper into the impacts of COVID-19 lockdown on noise pollution levels, this study investigates the changes in noise pollution levels before, during, and after lockdown phase in different residential, commercial, industri$\mathrm{al}$, and silence zones of the city of Kanpur, India. The purpose of this study is to examine the changes in noise levels during different phases of lockdown, examine the noise exceedance levels in different zones and the possible impact on annoyance and sleep disturbance, and propose efficient noise mitigation strategies to reduce the overall adverse effects of noise.

\section{Methodology}

\section{Characteristics of the study area}

Kanpur is one of the most important cities in the northern region of India and indeed the largest city in the state of
Uttar Pradesh. It is the major center of industrial and commercial activities of North India and is famous for being one of the largest centers of leather industries in the world. It is located in the state of Uttar Pradesh having latitude $26.4499^{\circ} \mathrm{N}$ and longitude $80.3319^{\circ} \mathrm{E}, 126 \mathrm{~m}$ above the mean sea level. The population of Kanpur city is 29.2 lakh (Census India 2011) spread over an area of $403.7 \mathrm{~km}^{2}$. The maximum and minimum temperatures are observed to be $33.3{ }^{\circ} \mathrm{C}$ and $3.7^{\circ} \mathrm{C}$, respectively, with an average rainfall of $820 \mathrm{~mm}$, average relative humidity of $78.13 \%$, and wind speed of $0.936 \mathrm{~km} / \mathrm{h}$.

Similar to the nationwide lockdown imposition in India, a complete lockdown in the city of Kanpur was implemented between 25th March 2020 and 31st May 2020. The lockdown restrictions were lifted from then, but several phases of unlock (or reopening) continued to be implemented. Phase I and phase II of unlock started from 1st June 2020 to 31 st July 2020 with complete 2-day weekend lockdown and night curfews being in effect from 10 to $6 \mathrm{pm}$. Later, during phase III and phase IV of unlock (1st August 2020 to 30th September), restrictions on weekend lockdown were lifted from 12th September 2020, and also night curfew was lifted.

To investigate the effects of noise exposure during different phases of lockdown, a total of six sampling locations were considered corresponding to residential, industrial, commercial, and silence zones of the Kanpur city. Location details of the noise monitoring stations are presented in Table 1, and the geographic spread of the locations is outlined in Fig. 1.

\section{Data collection procedure}

Collection of sound data was done from the environmental sensors established by Tech Mahindra under the project of smart city at each 1-h time interval. These are portable electro-chemical sensors manufactured by iRam technologies based on the Internet of Things (IoT) and cloud architecture. Vibrations of sound from different sources hit the sensors, and sensors convert the signals to analog data which and are then finally converted to noise level data in decibel. The sensors measure the noise level in the range of $30-120 \mathrm{~dB}$ with a resolution of $0.1 \mathrm{~dB}$. These wireless sensors are calibrated remotely in NABL (National Accreditation Board for Testing and Calibration Board of Quality Council of India) certified lab.

Table 1 Location details of the sound stations in Kanpur

\begin{tabular}{lll}
\hline Location ID & Zone & Sampling locations \\
\hline 1 & Silence (location I) & IIT Kanpur \\
2 & Silence (location II) & Mariampur \\
3 & Residential (location I) & Kidwai Nagar \\
4 & Residential (location II) & Deep Talkies \\
5 & Commercial & Gol Chauraha \\
6 & Industrial & Fazalganj \\
\hline
\end{tabular}


Fig. 1 Map showing sampling locations
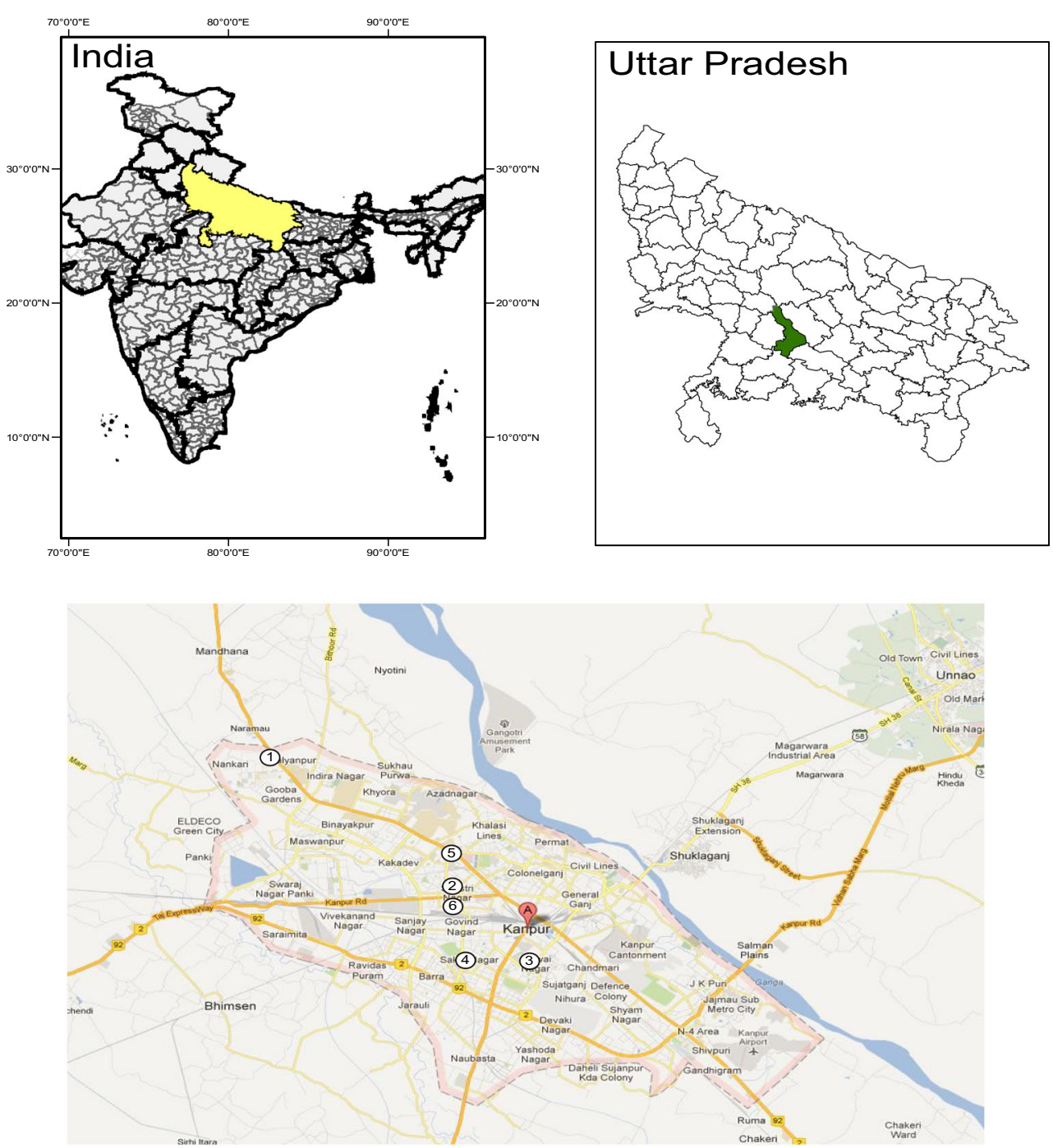

Using these sensors, data on sound levels were gathered over a period of $24 \mathrm{~h}$ between November 2019 to September 2020 , covering the complete phase of before lockdown, during lockdown, and during unlock phase.

\section{Noise assessment analysis}

To analyze the noise pollution level, noise percentiles values (i.e., L10, L50, and L90) were calculated by using noise level data, and these percentiles values were used to evaluate the noise pollution indices (Pathak et al. 2008; Robinson 1971). Hourly noise data were analyzed to obtain the equivalent sound level (Leq) for all the days of a month corresponding to specific hour:

$$
\begin{aligned}
& \mathrm{NC}=\mathrm{L} 10-\mathrm{L} 90 \\
& \mathrm{Leq}=\mathrm{L} 50+(\mathrm{NC})^{2} / 60
\end{aligned}
$$

where L10, L50, L90, NC, $\mathrm{L}_{\mathrm{eq}}$, and $\mathrm{L}_{\mathrm{np}}$ represent the level of sound exceeding for $10 \%$ of the total time of measurement, the level of sound exceeding for $50 \%$ of the total time of measurement, the level of sound exceeding for $90 \%$ of the total time of measurement, the equivalent noise level, and the noise pollution level, respectively. $\mathrm{L}_{\mathrm{eq}}$ represents the equivalent effect of noise coming from different sources and of varying intensities (Robinson 1971; Newman and Beallie 1985).

A descriptive analysis is performed of the sound levels in the considered sound monitoring locations during different phases of COVID-19 lockdown. The changes in sound levels in the pre-lockdown, lockdown, and unlock phase are assessed according to different land use patterns (residential, industrial, commercial, and silence zones). $t$-test for comparing two sample means and $F$-test for sample variances are applied to identify possible differences in the sound levels during lockdown phases, and analysis of variance (ANOVA) test is conducted for more than two considered 
samples. All these analyses are performed at a significance level of $5 \%$. Further, to examine noise impacts on public well-being, a possible estimate of the percentage of population at risk of high annoyance and sleep disturbance in all the considered zones are made based on the available literature.

\section{Annoyance and sleep disturbance}

Continuous exposure to traffic noise can cause sleep disturbance and annoyance which may lead to psychological, attitudinal, and physiological stress responses in some individuals (Babisch 2002; Guski et al. 2017; Basner and McGuire 2018). The present work employed two measures to estimate the population at high risk of being highly annoyed (\%HA) and percentage of people with high level of sleep disturbance (\%HSD), based on the exposure to traffic noise levels during different phases of lockdown.

Based on the equation developed by Miedema and Vos (1998), the percentage of population that is highly annoyed (\%HA) due to exposure to road traffic noise can be estimated as a function of day-night average sound level (DNL). They considered that the degree of annoyance is zero at a level of 42 $\mathrm{dB}$ or for sound levels below that and the equation is formulated as

$\% H A=0.24 *(D N L-42)+0.0277 *(D N L-42)^{2}$

The day-night average sound level is given by

$D N L=10 \log \frac{15^{*} 10^{L_{d} / 10}+9 * 10^{\left(L_{L}+10\right)} / 10}{24}$

where $L_{d}$ and $L_{n}$ are the 15-h day time (7:00-22:00) and 9-h night time (22:00-7:00) equivalent sound levels, respectively. Similarly, the percentage of people with high level of sleep disturbance (\%HSD) due to road traffic noise can be given by the equation formulated by Miedema et al. (2003):

$\% H S D=20.8-1.05 L_{n}+0.01486 L_{n}{ }^{2}$

\section{Results and discussion}

\section{Changes in sound levels according to different land uses}

A total of six locations were selected for sound level measurements corresponding to residential, industrial, commercial, and silence zones. The equivalent continuous sound level data were averaged over $1 \mathrm{~h}\left(\mathrm{~L}_{\mathrm{eq}}\right)$, and its monthly variation according to different land use types is presented in Fig. 2.

Although a wide variation in the monthly sound levels can be observed according to different land use types, there exists a prominent trend in the overall sound levels during different phases of lockdown. In particular, data processed between 25th March to 31st May 2020 (nationwide lockdown declaration in India) can be related to "during lockdown" phase, while the period before 25th March 2020 and after 31st May 2020 are defined as "before lockdown" and "unlock phase," respectively, in this study. While the equivalent sound levels for all zones lie in the range of $42-87 \mathrm{~dB}$ before lockdown period, it drastically reduced to $38-66 \mathrm{~dB}$ during lockdown, and then the range gradually increased to $41-76 \mathrm{~dB}$ (Fig. 2).

Concerning monthly differences in the equivalent sound levels, the results of analysis of variance (ANOVA) test indicated no significant differences in $L_{\mathrm{eq}}$ between November and February (before lockdown) and between June and September (unlock phase) for both the residential zones. Moreover, due to unavailability of residential zone data during May, statistical tests could not be performed for the residential zones during lockdown period. Before lockdown period, $L_{\mathrm{eq}}$ data of all the five months (November, December, January, February, and March) revealed significant differences in $L_{\text {eq }}$ for industrial $\left[\mathrm{F}_{\text {stat }}=8.56>\mathrm{F}_{\text {cri }}=2.45, p<0.001\right]$, commercial $\left[\mathrm{F}_{\text {stat }}=\right.$ $\left.15.82>\mathrm{F}_{\text {cri }}=2.45, p<0.001\right]$, and silence (location I) $\left[\mathrm{F}_{\text {stat }}=\right.$ $\left.25.16>\mathrm{F}_{\text {cri }}=2.45, p<0.001\right]$ zones, the only exception being location II of the silence zone where no statistical difference could be observed $\left[\mathrm{F}_{\text {stat }}=1.02<\mathrm{F}_{\text {cri }}=2.45, p=0.40\right]$. Further, statistical differences in the monthly data could be observed only for industrial $\left[\mathrm{F}_{\text {stat }}=23.35>\mathrm{F}_{\text {cri }}=3.13, p<\right.$ $0.01]$ and location $\mathrm{I}$ of the silence zone $\left[\mathrm{F}_{\text {stat }}=3.13>\mathrm{F}_{\text {cri }}=\right.$ $2.71, p<0.05]$ during unlock phase, while $t$-test for sample means indicated statistical differences during lockdown phase for all land use types.

Although differences in monthly $L_{\mathrm{eq}}$ data were observed for different zones, the equivalent sound level data were further grouped into three categories (according to before lockdown, during lockdown, and unlock phase) for a better understanding of the changes in sound level as a result of nationwide lockdown in India. A summary of the statistical properties of $L_{\mathrm{eq}}$ during different phases of lockdown for all land use types is presented in Table 2 .

Comparing the mean $L_{\mathrm{eq}}$ values, a distinct reduction in sound levels is observed during lockdown, which gradually increased after lockdown phase. The same trend follows for all land use types. The reduction in mean $L_{\mathrm{eq}}$ is found to be the maximum for location I of residential zone (29\%), followed by $23 \%$ reduction for location II of residential zone and location II of silence zone and $17 \%$ in location I of the silence zone. On the other hand, the reduction in $L_{\mathrm{eq}}$ is found be $8 \%$ and $14 \%$ for industrial zone and commercial zone, respectively.

Conversely, sound levels during unlock phase increased by $21 \%$ in the silence zones and location II of the residential zone as compared to sound levels during lockdown. It further 
Fig. 2 Monthly variation in $L_{e q}$ according to different land use types

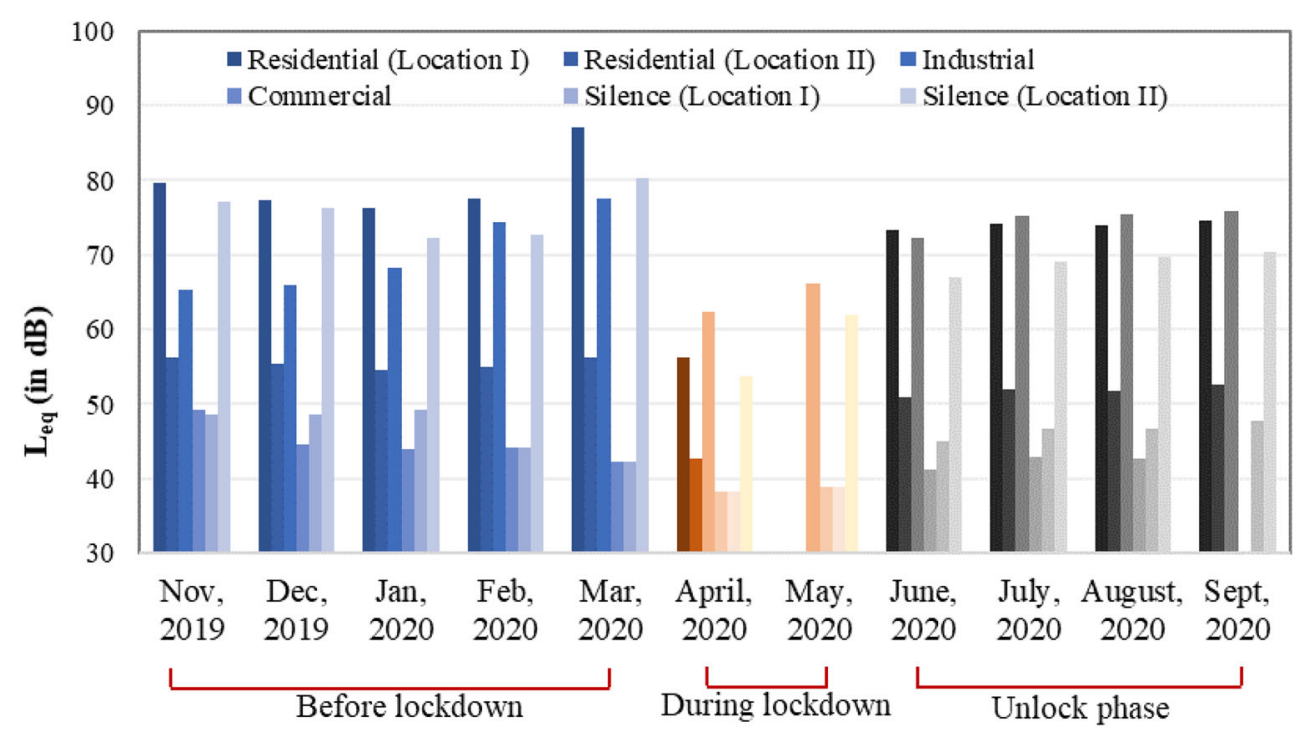

increased by $32 \%$ in location I of the residential zone, while the increment was found to be lower in the industrial $(16 \%)$ and commercial zones (9\%), respectively. These results indicate that the reduction in sound levels during lockdown was considerably higher in residential $(23 \mathrm{~dB}$ and $13 \mathrm{~dB}$ in location I and II, respectively) and silence ( $8 \mathrm{~dB}$ in location I and $18 \mathrm{~dB}$ in location II) zones than that of industrial and commercial zones ( $6 \mathrm{~dB}$ reduction in both the cases). This can certainly be attributed to the huge reduction in traffic, strict prohibition of individual's movement, and closure of businesses, the impact of which could be observed in residential and silence zones. On the other hand, to expedite the operation of manufacturing units and avoid shortage of any essential commodities, inter-state and intra-state movement of trucks and other categories of goods vehicles were permitted as a result of which the reduction in sound level in the industrial zone was not found to be significant.
To further attain additional insights into the statistical significance of equivalent sound levels during different phases of lockdown, $t$-test was conducted for comparing two sample means (Table 3). As expected, significant differences in mean $L_{\text {eq }}$ were obtained between data corresponding to before lockdown phase and during lockdown for all land use types. Similar observations were attained for $L_{\text {eq }}$ data belonging to during lockdown and unlock phase in all the cases. This clearly indicates that the sound level in all the zones reduced significantly during lockdown. It is also interesting to note that no significant differences in the sound levels could be observed before lockdown and during unlock phase for residential, industrial, commercial, and silence zones, which is an indication of normal traffic operations during unlock phase after the four phases of nationwide lockdown in India (starting from 25th March 2020 to 31st May 2020).

Table 2 Statistical summary of $L_{e q}$ during different phases of lockdown

\begin{tabular}{|c|c|c|c|c|c|c|c|c|c|c|c|c|}
\hline & \multicolumn{4}{|c|}{ Before lockdown } & \multicolumn{4}{|c|}{ During lockdown } & \multicolumn{4}{|c|}{ After lockdown } \\
\hline & Min & Mean & Median & Max & Min & Mean & Median & Max & Min & Mean & Median & Max \\
\hline \multicolumn{13}{|c|}{ Residential } \\
\hline $\mathrm{I}$ & 54.29 & 79.57 & 85.26 & 104.00 & 44.27 & 56.19 & 55.45 & 72.73 & 51.54 & 74.04 & 80.91 & 85.06 \\
\hline II & 39.03 & 55.40 & 59.99 & 67.71 & 37.82 & 42.66 & 42.09 & 51.00 & 38.59 & 51.86 & 55.73 & 63.07 \\
\hline \multicolumn{13}{|c|}{ Industrial } \\
\hline & 48.26 & 70.27 & 72.23 & 88.56 & 53.45 & 64.19 & 62.12 & 76.64 & 54.02 & 74.71 & 79.80 & 86.44 \\
\hline \multicolumn{13}{|c|}{ Commercial } \\
\hline & 38.93 & 44.83 & 44.85 & 56.00 & 37.71 & 38.55 & 38.34 & 39.85 & 38.89 & 42.24 & 42.13 & 45.33 \\
\hline \multicolumn{13}{|c|}{ Silence } \\
\hline I & 38.94 & 46.57 & 46.07 & 54.41 & 37.71 & 38.55 & 38.35 & 39.85 & 39.80 & 46.49 & 47.11 & 51.61 \\
\hline II & 45.71 & 75.71 & 83.13 & 101.27 & 40.75 & 57.79 & 56.65 & 78.11 & 43.37 & 69.07 & 76.05 & 85.52 \\
\hline
\end{tabular}


Table $3 t$-stat results of $L_{e q}$ during different phases of lockdown

\begin{tabular}{|c|c|c|c|c|c|}
\hline & & During & & Unlock & \\
\hline Residential (location I) & $\begin{array}{l}\text { Before } \\
\text { During }\end{array}$ & $8.30(p<0.001)$ & Significant & $\begin{array}{l}\mathbf{1 . 9 8}(\boldsymbol{p}=\mathbf{0 . 0 9}) \\
-6.37(p<0.001)\end{array}$ & $\begin{array}{l}\text { Not significant } \\
\text { Significant }\end{array}$ \\
\hline Residential (location II) & $\begin{array}{l}\text { Before } \\
\text { During }\end{array}$ & $6.26(p<0.001)$ & Significant & $\begin{array}{l}1.40(p=\mathbf{0 . 0 8}) \\
-4.94(p<0.001)\end{array}$ & $\begin{array}{l}\text { Not significant } \\
\text { Significant }\end{array}$ \\
\hline Industrial & $\begin{array}{l}\text { Before } \\
\text { During }\end{array}$ & $2.80(p<0.01)$ & Significant & $\begin{array}{l}-1.61(p=0.06) \\
-4.43(p<0.01)\end{array}$ & $\begin{array}{l}\text { Not significant } \\
\text { Significant }\end{array}$ \\
\hline Commercial & $\begin{array}{l}\text { Before } \\
\text { During }\end{array}$ & $10.17(p<0.001)$ & Significant & $\begin{array}{l}1.57(p=0.09) \\
-9.05(p<0.001)\end{array}$ & $\begin{array}{l}\text { Not significant } \\
\text { Significant }\end{array}$ \\
\hline Silence (location I) & $\begin{array}{l}\text { Before } \\
\text { During }\end{array}$ & $13.13(p<0.001)$ & Significant & $\begin{array}{l}\mathbf{0 . 0 9}(\boldsymbol{p}=\mathbf{0 . 4 6}) \\
-12.65(p<0.001)\end{array}$ & $\begin{array}{l}\text { Not significant } \\
\text { Significant }\end{array}$ \\
\hline Silence (location II) & $\begin{array}{l}\text { Before } \\
\text { During }\end{array}$ & $4.73(p<0.001)$ & Significant & $\begin{array}{l}1.49(p=0.07) \\
-3.00(p<0.01)\end{array}$ & $\begin{array}{l}\text { Not significant } \\
\text { Significant }\end{array}$ \\
\hline
\end{tabular}

Note: Bold features indicate no statistical difference between the samples
Furthermore, the distributions of equivalent sound levels (presented in Fig. 3) for the residential zones indicate that $53 \%$ of the data were in between 80 and $90 \mathrm{~dB}$ before lockdown in location I and $50 \%$ data in the range of $60-70 \mathrm{~dB}$ corresponded to location II. During lockdown, the sound levels were mostly observed between $50-60 \mathrm{~dB}$ and $40-50$ $\mathrm{dB}$ in location I and location II, respectively. While most of the sound level data in the industrial zone were between 70 and $80 \mathrm{~dB}$ before lockdown, the mode increased to $80-90 \mathrm{~dB}$ after lockdown. Also, 34\%, 38\%, and $27.7 \%$ data corresponded to $50-60 \mathrm{~dB}, 60-70 \mathrm{~dB}$, and $70-80 \mathrm{~dB}$, respectively, during lockdown phase. In parallel, $L_{\mathrm{eq}}$ in the commercial zone lies in the range of 30-60 $\mathrm{dB}$ before lockdown, the mode being observed at $40-50 \mathrm{~dB}$ for data corresponding to both pre-lockdown and unlock phases.

However, all the sound level data were in between 30 and $40 \mathrm{~dB}$ during lockdown in the commercial zone. Comparing the sound level distributions of the silence zones, the range of $L_{\text {eq }}$ lies in between 30-60 dB and 40-100 dB before lockdown, the range being almost similar for data during unlock phase as well. While $100 \%$ of the data in location I corresponded to $30-40 \mathrm{~dB}$ during lockdown, a wide variation in the data could be observed for location II of the silence zone. $L_{\mathrm{eq}}$ data during lockdown were observed in between 40 and $100 \mathrm{~dB}$, with $27 \%$ data corresponding to $60-70 \mathrm{~dB}$. This is because location II of the silence zone is near a rotary and is surrounded by hospitals and medical institutes. The wide variation in sound levels between 40 and $100 \mathrm{~dB}$ even during lockdown is due to comparatively higher traffic volumes and also because of the operation of emergency medical services near that location.

These results signify that there has been a prominent decline in equivalent sound levels during lockdown. Comparing modes of the histograms, it can be observed that the range of $L_{\text {eq }}$ reduces by approximately $10 \mathrm{~dB}$ during lockdown as compared to the range before lockdown for location II of the residential zone, industrial, commercial, and location I of silence zone. Conversely, the reduction is by almost $20 \mathrm{~dB}$ for location II of the silence zone and by $30 \mathrm{~dB}$ for location I of the residential zone. This illustrates that nationwide lockdown has caused significant changes in the sound levels in different types of land uses.

\section{Time-wise variations in equivalent sound levels}

The temporal variations of equivalent sound level during different phases of lockdown are further presented in Fig. 4 with respect to different land use types. In all the cases, the reduction in $\mathrm{L}_{\mathrm{eq}}$ during lockdown can be clearly visible although the range of sound levels are different for different zones. Moreover, the changing patterns in sound levels indicate two definite peaks - the first peak occurring in the morning and the second peak in the evening period. While distinct peaks in $\mathrm{L}_{\mathrm{eq}}$ data are observed in the residential zones, industrial zone, and location II of the silence zone during lockdown, no such pattern follows for commercial land use and location I of the silence zone over different time periods. These zones (commercial and location I of silence land use) show no significant changes in $\mathrm{L}_{\mathrm{eq}}$ level even before the lockdown and during unlock phase as well.

Interestingly, the two distinct noisy periods are observed only during lockdown phase. The hourly pattern of sound before lockdown and during unlock phase shows an increase in sound levels, reaches peak, remains consistent for a longer time span till approximately $9 \mathrm{pm}$, and then follows a decreasing trend. However, the peak sound level in the morning during lockdown occurs between 8 and 9 am for almost all the zones. Although there is an increase in $\mathrm{L}_{\mathrm{eq}}$ in the evening period, the peak is much smaller, and it does not reach morning levels. 
Fig. 3 Frequency distribution of sound level before, during, and after lockdown period at a residential (location I), b residential (location II), $\mathbf{c}$ industrial, $\mathbf{d}$ commercial, e silence (location I), and (f) silence (location II) zones

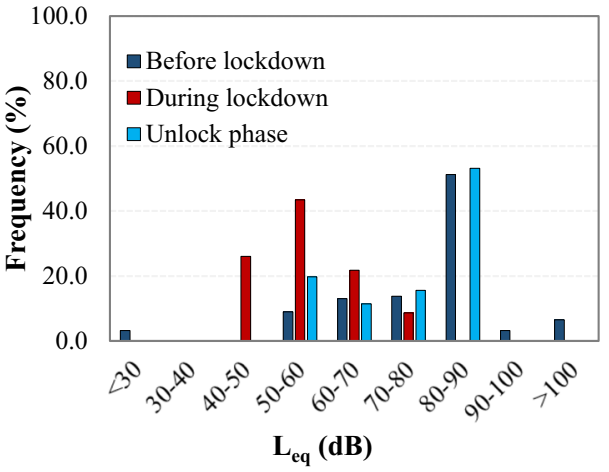

(a)

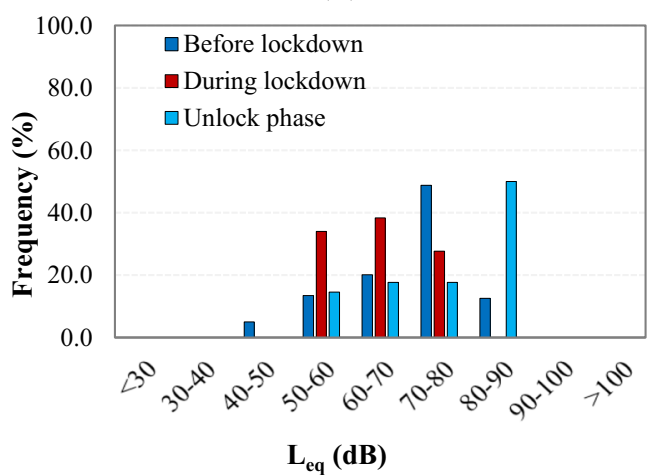

(c)

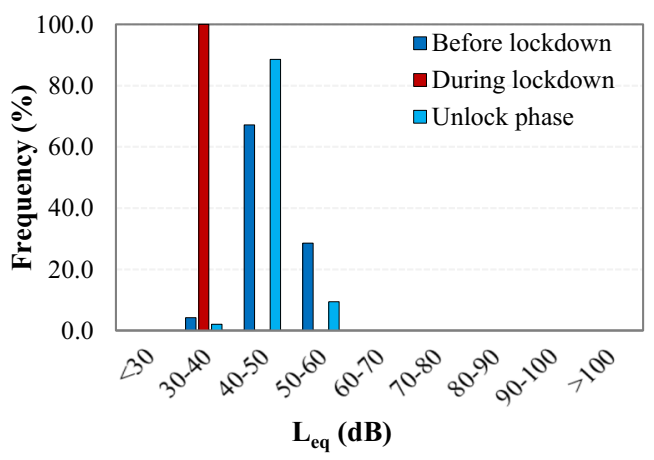

(e)

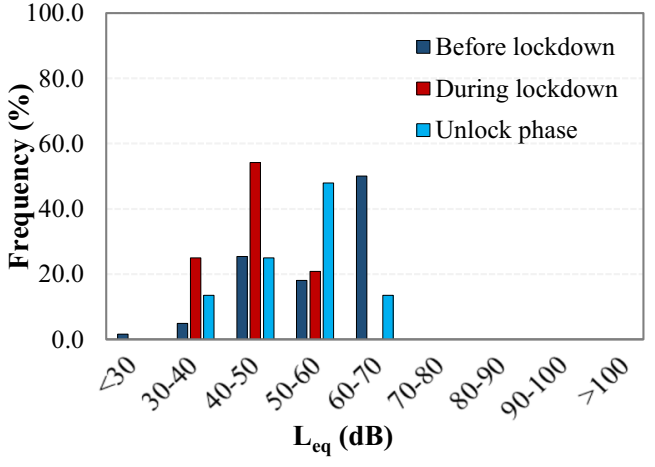

(b)

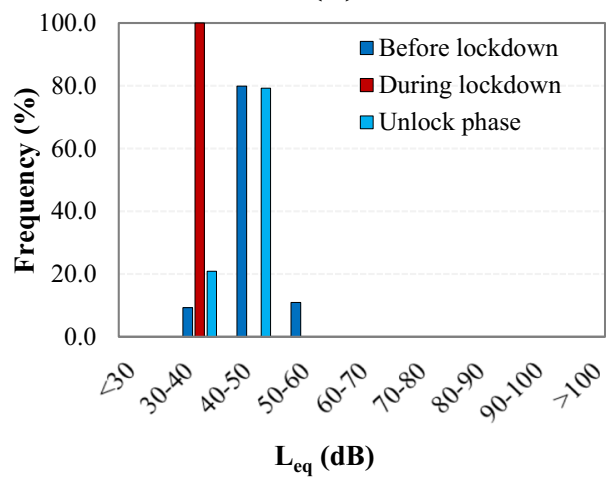

(d)

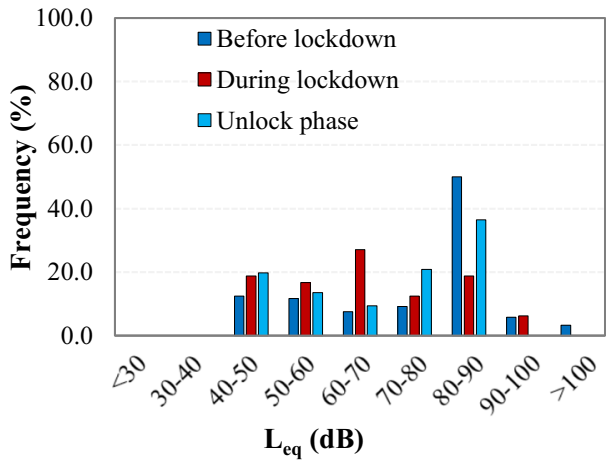

(f)
The morning peaks in the residential locations can be due to continuous operation of essential services during the lockdown period, increased human mobility to meet household needs in the morning hours, and also due to movement of stranded people to their own residences. Also, because some industrial establishments were functioning during lockdown, a small peak could be observed in the morning hours in the industrial area. On the other hand, the commercial and private establishments were shut down, and as such no peak in the sound level was visible. Concerning both the locations of silence zone, location I (near IIT Kanpur) is a rural area near one of the institutes of national importance, while location II (Mariampur) is an urban area in the vicinity of a rotary and surrounded by hospitals and medical institutes. Comparing both these locations, comparatively higher level of sound could be observed in the Mariampur area than that near IIT Kanpur. This can be attributed to higher traffic volumes in the Mariampur area due to changes in speed, acceleration, and deceleration along with honking near the intersection and also due to the operation of emergency medical services near that location in the morning as well as evening hours.

The figure clearly illustrates that the sound patterns change considerably over different time periods possibly due to changes in traffic patterns as well as other human activities. In an attempt to provide a deeper understanding on the changing sound levels in the morning and evening period during different phases of lockdown, the 24-h period is subdivided into two timeframes: day time ( 6 am to $10 \mathrm{pm}$ ) and night time (10 pm to $6 \mathrm{am})$. The average equivalent sound for day time and night time are denoted as $L_{d}$ and $L_{n}$, respectively. Table 4 
Fig. 4 Time-wise variation in $L_{e q}$ during different phases of lockdown for a residential land use (location I), b residential (location II), c industrial land use, d commercial land use, e silence zone (location I), and $\mathbf{f}$ silence zone (location II)

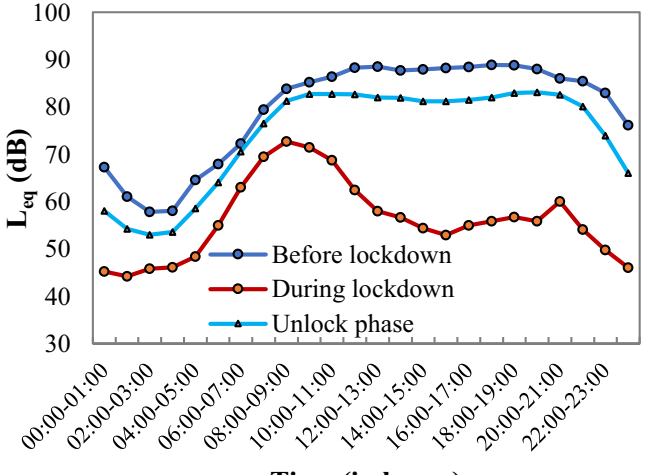

Time (in hours)

(a)

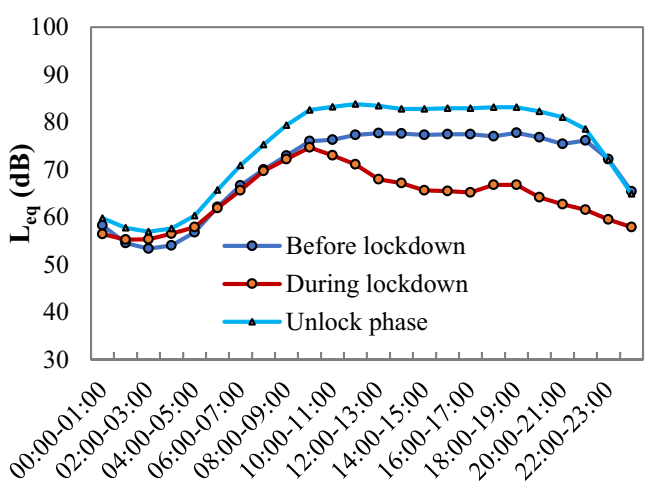

Time (in hours)

(c)

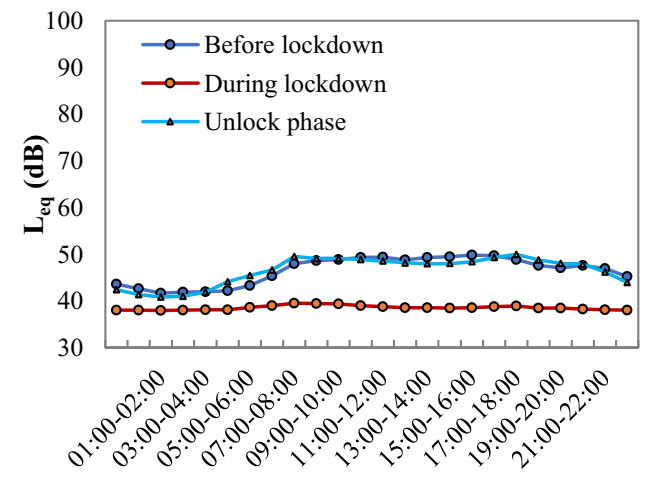

Time (in hours)

(e)

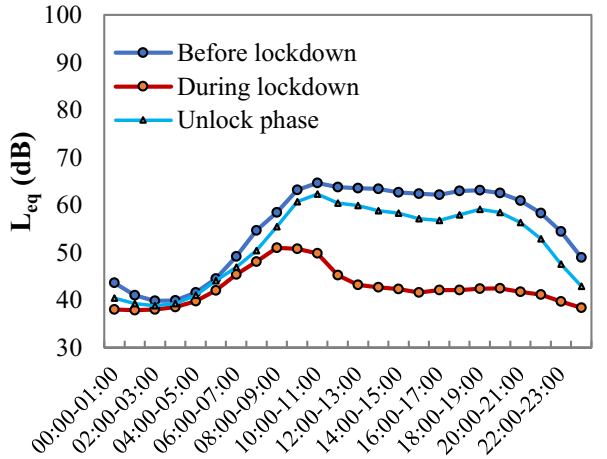

Time (in hours)

(b)

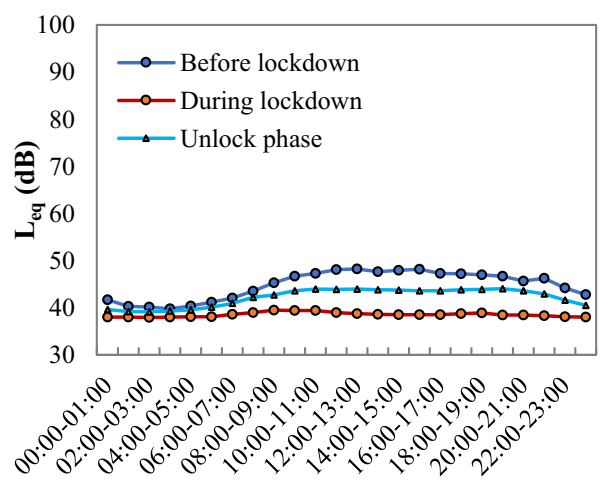

Time (in hours)

(d)

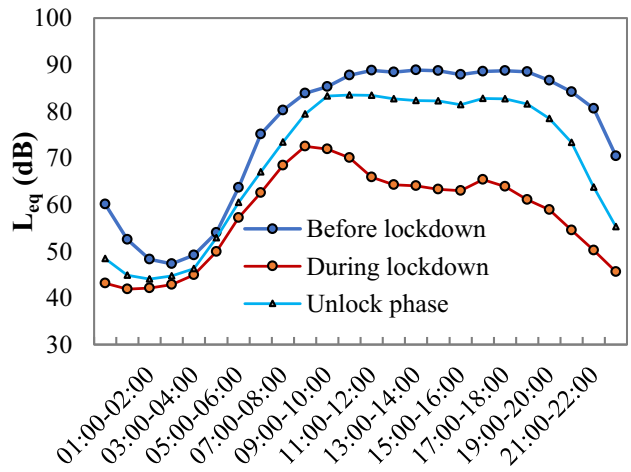

Time (in hours)

(f)
Table 4 Statistical summary of average equivalent sound during day time and night time

\begin{tabular}{|c|c|c|c|c|c|c|}
\hline \multirow[t]{2}{*}{ Land use } & \multicolumn{2}{|c|}{ Before lockdown } & \multicolumn{2}{|c|}{ During lockdown } & \multicolumn{2}{|l|}{ Unlock } \\
\hline & Day time & Night time & Day time & Night time & Day time & Night time \\
\hline Residential (I) & 99.03 & 84.35 & 77.43 & 64.30 & 93.63 & 76.55 \\
\hline Residential (II) & 74.11 & 57.28 & 57.81 & 50.07 & 70.24 & 52.98 \\
\hline Industrial & 88.32 & 74.49 & 81.01 & 69.47 & 94.02 & 75.89 \\
\hline Commercial & 58.79 & 51.18 & 50.59 & 47.65 & 55.37 & 49.64 \\
\hline Silence (I) & 60.49 & 52.33 & 50.54 & 47.28 & 60.37 & 52.71 \\
\hline Silence (II) & 98.92 & 76.67 & 78.54 & 64.05 & 93.06 & 68.33 \\
\hline
\end{tabular}


presents the average equivalent value during day and night time for all the zones.

The hourly average equivalent sound level for day and night time in the pre-lockdown, lockdown, and after lockdown period indicates that the sound levels during day time are considerably higher than night time in all the zones. This is in line with the observed peaks in sound level as presented in Fig. 4. Also, changes in sound level clearly depict reduction in sound during lockdown which then increases after lockdown phase. While the equivalent sound levels were found to vary according to different land use types, commercial zone and location I of silence zone exhibited approximately similar sound levels during day and night time in the pre-lockdown and lockdown period, a slight variation being observed during unlock phase.

The average reduction in sound levels in night time before lockdown and during unlock phase is almost $15 \mathrm{~dB}$, the maximum reduction being observed in location II of the silence zone (22 and $25 \mathrm{~dB}$ in pre-lockdown and unlock period, respectively) and the minimum in the commercial zone $(7 \mathrm{~dB}$ in pre-lockdown phase), whereas the average sound level drops by $9 \mathrm{~dB}$ during lockdown in all the zones. While the reduction in sound level during night (as compared to day time) before lockdown is in between 13 and $23 \%$, the range is found to be 6-18\% during lockdown and 10-26\% during unlock phase. In the lockdown period, reduction in sound levels is found to be higher in residential areas, industrial zone, and location II of the silence zone. Comparing day time noise equivalents in the pre-lockdown and lockdown period, $22 \%$ reduction in sound equivalents is obtained for residential zones and location II of the silence zone, $15 \%$ for commercial and location I of silence zone, and $8 \%$ reduction is obtained for the industrial zone. Also, reduction in night time sound equivalents before lockdown indicates that the reduction is maximum for location I of residential zone (24\%), followed by location II of silence zone $(16 \%)$, location II of residential zone (13\%), and $7 \%$ for industrial and commercial zone.

The Central Pollution Control Board (CPCB) of India has recommended noise limits of 55 and $45 \mathrm{~dB}$ during day time and night time in residential areas; 75 and $70 \mathrm{~dB}$ in industrial areas; 65 and $55 \mathrm{~dB}$ in commercial; and 50 and $40 \mathrm{~dB}$ during the day and night time in silence zones. Considering the prescribed limits, the percentage of times the hourly equivalent sound level exceeds the threshold values in the pre-lockdown, lockdown, and unlock phase during day and night time are presented in Fig. 5. Location I of the residential zone and location II of silence zone had recorded sound exceeding the threshold $100 \%$ of the times during both day and night time in the pre-lockdown and unlock period. Except for commercial and industrial zone in the pre-lockdown period, all other zones showed more than $80 \%$ exceedance during day time in prelockdown and unlock period. However, during night, location II of residential zone and industrial zone had exceedance levels comparatively lower than that in the day time. Also, location I of the residential zone and location II of silence zone are not found to meet the noise standards at any time in the pre-lockdown and unlock period.

During lockdown, the percentage of times that sound exceeded the standard limits reduced considerably for most of the stations, the exceptions being residential (location I) and silence (location II) zones. More than $93 \%$ of the time the hourly equivalent sound exceeded $50 \mathrm{~dB}$ during day time in the silence zone (location II) and during night time; 100\% exceedance was observed even during lockdown. For the residential zone (location I), the threshold was followed for only $25 \%$ of the time during day and $12 \%$ of the time the sound was within the night time threshold limit of $55 \mathrm{~dB}$. Conversely, commercial zone and location I of silence zone indicated that $100 \%$ of the times, sound was within the threshold limit during both day and night times. Location II of residential zone and industrial zone also showed lower percentage of exceedance. Although the reduction in equivalent sound levels can be clearly observed during lockdown for residential (location II), industrial, and silence (location I) zones, location I of the residential zone and location II of silence zones showed no significant improvement. The only exception is with the commercial zone where sound level was observed to be lower than the recommended limit all the times in different phases of lockdown.

These results indicated that the locations in the vicinity of Kidwai Nagar (location I of residential zone) and Mariampur area (location II of silence zone) were profoundly affected by noise pollution and their levels were above the legal noise limits for $100 \%$ of the times in the pre-lockdown and unlock phase and more than $75 \%$ exceedance was during lockdown period. This can be due to the presence of nearby intersections in the vicinity of the monitoring stations where vehicles are more likely to generate higher levels of noise due to changes in speed, acceleration, and deceleration patterns.

\section{Noise impact assessment: annoyance and sleep disturbance}

Continuous exposure to noise can have a long-term impact on the person's health and well-being. It can cause sleep disturbance and annoyance which may lead to psychological, attitudinal, and physiological stress responses in some individuals (Babisch 2002; Guski et al. 2017; Basner and McGuire 2018). Except for commercial zone, all the monitoring stations considered in this work had reported sound levels quite higher than the recommended noise limits. In particular, location I of the residential zone and location II of the silence zone showed more than $87 \%$ exceedance of standard noise limits even during night time in the lockdown period. This is indeed a subject of serious concern which may directly question the well-being 
Fig. 5 Percentage of time the hourly equivalent sound exceeded the standard noise limits in all the phases of lockdown during a day time and $\mathbf{b}$ night time

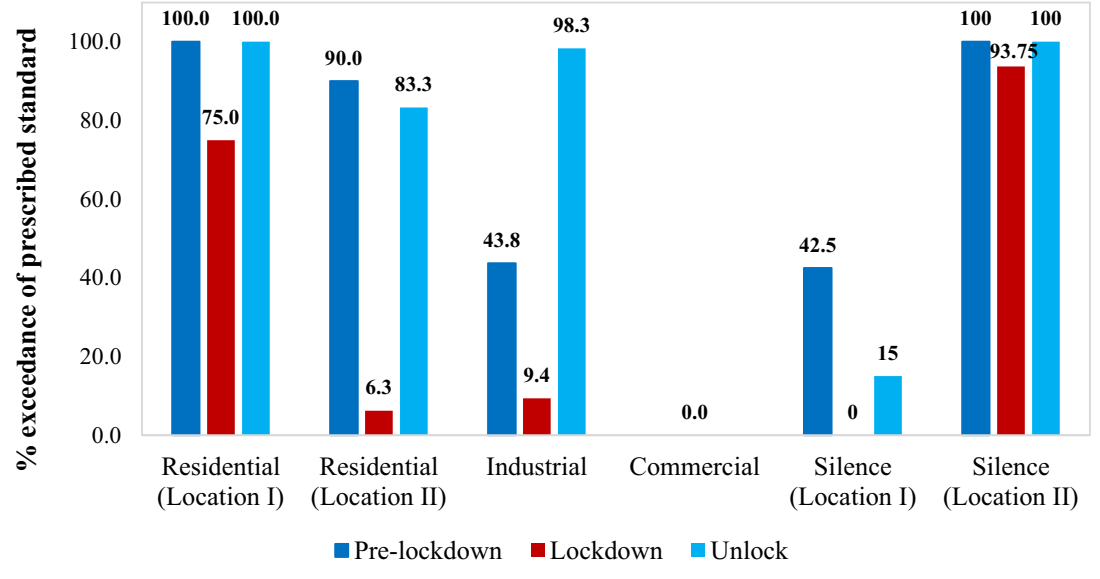

(a)

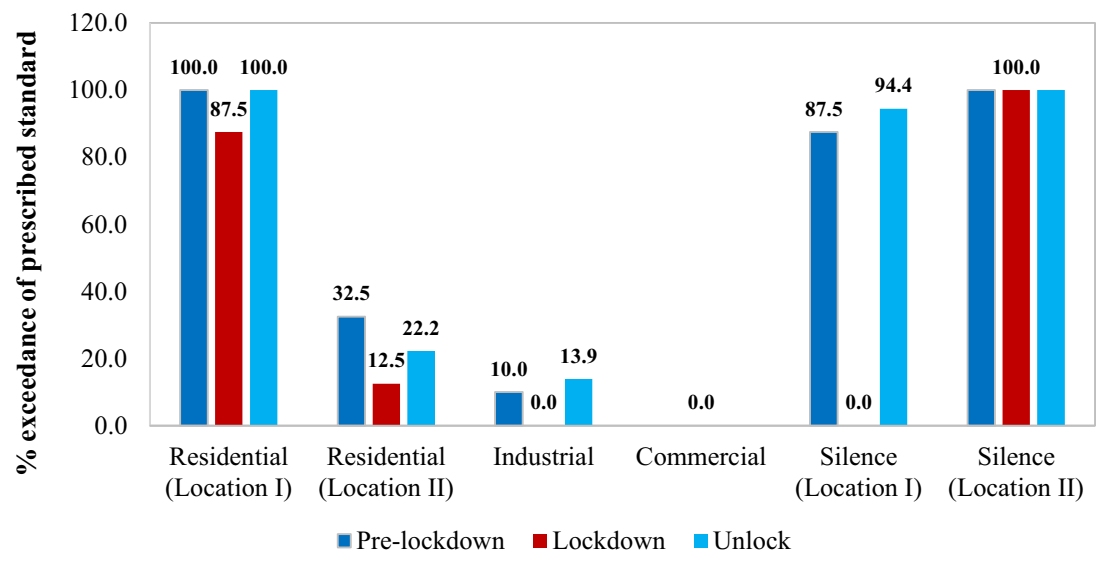

(b) of the people residing in the nearby areas. In an attempt to assess the impact of noise exposure on individuals' well-being, this section primarily aims at providing a possible estimate of the percentage of population at risk of high annoyance and sleep disturbance in all the zones.

The possible impacts of road traffic on annoyance and sleep disturbance in all the considered zones during different phases of lockdown are presented in Table 5.
The results indicate that residents of Kidwai Nagar (location I of residential zone) and Mariampur (location II of silence zone) and people living near Fazalganj (industrial zone) were estimated to be at severe risk of being highly annoyed in the pre-lockdown and unlock phase, and the risk of annoyance almost reduced to half during lockdown. Also, people living in the vicinity of these locations were at risk of having high levels of sleep disturbance. Compared with other zones,
Table 5 Annoyance level and percentage of sleep disturbance during different phases of lockdown according to land use type

\begin{tabular}{|c|c|c|c|c|c|c|c|c|c|}
\hline \multirow{2}{*}{$\begin{array}{l}\text { Land use } \\
\text { type }\end{array}$} & \multicolumn{3}{|c|}{ Before lockdown } & \multicolumn{3}{|c|}{ During lockdown } & \multicolumn{3}{|c|}{ Unlock phase } \\
\hline & $\begin{array}{l}\text { DNL } \\
(\mathrm{dB})\end{array}$ & $\begin{array}{l}\text { HA } \\
(\%)\end{array}$ & $\begin{array}{l}\text { HSD } \\
(\%)\end{array}$ & $\begin{array}{l}\text { DNL } \\
(\mathrm{dB})\end{array}$ & $\begin{array}{l}\text { HA } \\
(\%)\end{array}$ & $\begin{array}{l}\text { HSD } \\
(\%)\end{array}$ & $\begin{array}{l}\text { DNL } \\
(\mathrm{dB})\end{array}$ & $\begin{array}{l}\text { HA } \\
(\%)\end{array}$ & $\begin{array}{l}\text { HSD } \\
(\%)\end{array}$ \\
\hline Residential I & 97.80 & 86.23 & 37.96 & 76.50 & 41.25 & 14.72 & 92.07 & 81.47 & 27.50 \\
\hline Residential II & 72.58 & 28.87 & 9.41 & 58.80 & 11.85 & 5.48 & 68.66 & 26.09 & 6.88 \\
\hline Industrial & 87.24 & 87.44 & 25.04 & 80.49 & 50.28 & 19.57 & 92.36 & 82.34 & 26.70 \\
\hline Commercial & 59.85 & 8.16 & 5.99 & 54.62 & 7.44 & 4.51 & 57.48 & 10.36 & 5.29 \\
\hline Silence I & 61.27 & 13.76 & 6.55 & 54.33 & 7.17 & 4.37 & 61.40 & 15.08 & 6.74 \\
\hline Silence II & 97.03 & 84.47 & 27.65 & 77.34 & 43.07 & 14.51 & 91.11 & 78.58 & 18.43 \\
\hline
\end{tabular}


residents of Kidwai Nagar are considered to be the most negatively affected due to road traffic noise. This demonstrates the need to consider suitable noise reduction measures in the residential zone to protect the residents from any health disorder and psychological stresses.

The area near Deep Talkies (location II of residential zone) also showed the impact of road traffic noise where 29 and $27 \%$ of people were anticipated to be highly annoyed in the pre-lockdown and unlock phase, respectively, the percentage being reduced to $12 \%$ in the lockdown period. Although the risk of sleep disturbance was higher in the pre-lockdown period, it reduced to $5.48 \%$ during lockdown. Commercial zone exhibited lower risk of high annoyance and sleep disturbance among all the considered zones. Similarly, the percentage of highly annoyed people living near IIT Kanpur area (location I of silence zone) before lockdown was estimated as $13 \%$, which reduced to $7 \%$ during lockdown and then increased to $15 \%$ in the unlock phase. Also, the percentage of people who had high levels of sleep disturbance near IIT Kanpur during lockdown decreased from $6.55 \%$ before lockdown to $4.37 \%$, and then the percentage increased to $6.74 \%$ in the unlock phase.

Although the Kidwai Nagar and Mariampur locations indicated sound levels exceeding the recommended noise limits most of the times during all phases of lockdown, the impact of road traffic noise on the risk of high annoyance and sleep disturbance was found to be lower during lockdown as compared to that of pre-lockdown and unlock phase. In both these locations, the percentage reduced to half of that estimated in the pre- and post-lockdown period. In short, these results indicated that prominent reduction in annoyance and sleep disturbance level could be observed in the lockdown period, much better than the pre-lockdown and unlock phase. This suggests that strict noise pollution mitigation strategies and suitable policy measures could provide public health benefits and provide an overall sustainable transport infrastructure.

\section{Policy implications}

The key empirical findings of this work indicated prominent reduction in noise levels during lockdown period in all the considered zones. Higher sound levels in the Kidwai Nagar and Mariampur area can be attributed to the fact that the monitoring stations are located in close proximity to nearby intersections where changes in speed, acceleration, and deceleration of vehicles contributed to higher sound levels. It is noteworthy to mention that the Mariampur monitoring station is surrounded by hospitals and medical institutes which indeed showed sound exceeding the recommended noise limit most of the times. This prolonged exposure to excessive noise can detrimentally impact the safety and quality of healthcare and may delay the overall healing and recovering process of hospital patients.
With the implementation of nationwide and state lockdown programs, there were travel restrictions causing reduction in traffic and number of honking incidents. Although essential and emergency services were operational during lockdown, there were restrictions in human mobility, social, economic, commercial, and other industrial activities. Recognizing that transportation noise can adversely impact people's well-being, lifestyle, and local economy, many aspects of lockdown period can be considered further for devising new policies and guidelines towards noise pollution abatement. Although it is not feasible to impose lockdown or eliminate traffic from the cities, proper traffic management strategies can control the negative effects of noise pollution. Several possible policy implications obtained from this research are summarized below.

Promoting sustainable mode of transport Results of this study demonstrate that significant reduction in noise levels can be achieved through stringent traffic reduction strategies. Several interventions such as no honking policy, substitution of motorized private transport by active transport mode such as walking and cycling for short trips, parking management, and restricting access for the noisiest vehicles can reduce noise pollution, improve road safety, provide recreational value to all the users, and improve health of the communities. While cycling and walking offer health benefits and reduce noise, emissions, and congestion, providing proper bicycle paths and walkways is equally important for the efficient mobility of cyclists and pedestrians.

Adoption of greener environment The characteristics of the built environment such as view or access to green spaces in the neighborhood or having access to a quiet area can reduce annoyance (Gidlöf-Gunnarsson and Öhrström 2010; van Renterghem and Botteldooren 2012; Öhrström et al. 2006) and the negative response to road traffic noise. The construction of green belts around roads, vegetation, and incorporation of green spaces in the cities or even green roof installations can be considered as several measures to help attenuate noise exposure especially in the residential, silence, and industrial zones as considered in this research.

Road infrastructure Consideration of noise-reducing pavements, traffic noise impedance walls, and quieter vehicles and installation of natural or artificial noise barriers, no-horn sign, and other traffic-calming measures can reduce noise level at high sound level zones. Implementation of such measures in residential, silence, and commercial zones can provide a livable, workable, and healthy environment for the people residing in nearby areas.

Development of noise monitoring database Empirical results of this study demonstrated higher sound levels exceeding the 
noise limits in the residential, industrial, and silence zones. This can be directly associated with the heightened risks of individuals' well-being, health, psychological stresses, sleep disturbance levels, and other heart diseases. The development of a wide sound monitoring network can help in assessing higher sound levels and also the effectiveness of noise pollution mitigation strategies. The installation of sound monitoring stations across the cities and the development of a suitable noise monitoring database can direct towards the ill effects of noise exposure in different areas and identify communities that could be at high risk of noise pollution; comprehensive health impact assessment can be examined, and suitable policy measures can be devised in appropriate locations for protecting the health of the city and the environment.

Understanding the negative effects of noise exposure to the health and safety of individuals, it is important to closely monitor sound levels in the high-risk zones with a belief that the well-being of the communities can be protected only if appropriate actions and decisions are taken in due course of time.

\section{Conclusions}

This study attempted to investigate to what extent the COVID-19 lockdown has impacted exposure to noise pollution levels in the city of Kanpur, India. The behavioral shifts in transport sector and the societal lockdown have impacted positively on the local and regional environmental pollution levels. In this regard, this study provided an understanding of monthly sound level patterns, time-wise variations in sound data, changes in sound levels during different phases of lockdown, and possible risks due to prolonged exposure to noise pollution. The magnitude of changes in sound levels in the residential, industrial, commercial, and silence zones are examined in the pre-lockdown, lockdown, and after lockdown phase.

Our results indicated a significant reduction in sound levels at all the six sound monitoring stations during lockdown phase as compared to that of pre-lockdown and unlock phases. The reduction was much higher in the residential and silence zones than that of industrial and commercial zones. Concerning day and night time sound equivalent levels, the sound levels during day time were found to be considerably higher than night time in all the zones. The night time sound equivalent dropped by an average of $9 \mathrm{~dB}$ during lockdown, while the average reduction was by almost $15 \mathrm{~dB}$ in the pre-lockdown and unlock phase in all the considered zones. Considering the limits recommended by the Central Pollution Control Board (CPCB) of India, except for commercial zone, all other monitoring stations had reported sound levels quite higher than the recommended noise limits. In particular, the locations in the vicinity of Kidwai Nagar (location I of residential zone) and Mariampur area (location II of silence zone) showed more than $75 \%$ exceedance of the standard noise limits even during lockdown period, while it reached $100 \%$ in the pre-lockdown and unlock phase. This is indeed a subject of serious concern as continuous exposure to noise can have a long-term impact on a person's well-being such as annoyance and sleep disturbance.

Although the Kidwai Nagar and Mariampur locations indicated sound levels exceeding the recommended noise limits most of the times during all phases of lockdown, the impact of road traffic noise on the risk of high annoyance and sleep disturbance was found to be lower during lockdown as compared to that of pre-lockdown and unlock phase. The results of this work indicated that prominent reduction in annoyance and sleep disturbance level could be observed in the lockdown period, much better than the pre-lockdown and unlock phase. This suggests that strict noise pollution mitigation strategies and suitable policy measures could provide public health benefits and provide an overall sustainable transport infrastructure. In light of this, several possible noise mitigation strategies such as promoting sustainable mode of transport, adoption of green space, adequate road infrastructure, and development of a sound monitoring network in the local and regional level were also indicated in this work.

Acknowledgements The data used in this work is provided by Kanpur Smart City Limited (KSCL) as a part of smart city mission for the city of Kanpur, Uttar Pradesh. The authors would like to acknowledge the team of KSCL for their help and support in assembling the data.

Author contributions Conceptualization, Anirudh Mishra, Deepesh Singh, and Akhilesh Kumar Maurya; investigation, Anirudh Mishra and Deepesh Singh; methodology, Sanhita Das; resources, Anirudh Mishra and Deepesh Singh; formal analysis, Sanhita Das; writing — original draft, Sanhita Das and Anirudh Mishra; visualization, Sanhita Das; supervision, Deepesh Singh and Akhilesh Kumar Maurya; validation: Deepesh Singh and Akhilesh Kumar Maurya; writing - review and editing, Deepesh Singh and Akhilesh Kumar Maurya.

Availability of data and materials The datasets generated and/or analyzed during the current study are not publicly available because this data is collected as a part of the Smart Cities Mission of the Government of India.

\section{Declarations}

Ethics approval and consent to participate Not applicable.

Consent for publication Not applicable.

Competing interests The authors declare no competing interests. 


\section{References}

Abo-Qudais S, Alhiary A (2004) Effect of distance from road intersection on developed traffic noise levels. Can J Civ Eng 31(4):533-538

Amoatey P, Omidvarbona H, Baawain MS, Al-Mayahi A, Al-Mamun A, Al-Harthy I (2020) Exposure assessment to road traffic noise levels and health effects in an arid urban area. Environ Sci Pollut Res 27(28):35051-35064

Babisch W (2002) The noise/stress concept, risk assessment and research needs. Noise \& Health 4(16):1-11

Banerjee D, Chakraborty SK, Bhattacharyya S, Gangopadhyay A (2008) Evaluation and analysis of road traffic noise in Asansol: an industrial town of eastern India. Int J Environ Res Public Health 5(3):165-171

Basner M, McGuire S (2018) WHO environmental noise guidelines for the European region: a systematic review on environmental noise and effects on sleep. Int J Environ Res Public Health 15:519

Bhadram V (2003) Noise pollution status in Visakhapatnam city. Nat Environ Pollut Technol 2(2):217-219

Bhosale BJ, Late A, Nalawade PM, Chavan SP, Mule MB (2010) Studies on assessment of traffic noise level in Aurangabad city, India. Noise and Health 12(48): 195-198

Census India (2011) Retrieved from https://www.census2011.co.in/ census/city/131-kanpur.html

Dratva J, Zemp E, Dietrich DF, Bridevaux PO, Rochat T, Schindler C, Gerbase MW (2010) Impact of road traffic noise annoyance on health-related quality of life: results from a population-based study. Qual Life Res 19(1):37-46

Eriksson C, Nilsson ME, Willers SM, Gidhagen L, Bellander T, Pershagen G (2012) Traffic noise and cardiovascular health in Sweden: the roadside study. Noise and Health 14(59):140-147

Fuks KB, Weinmayr G, Basagaña X, Gruzieva O, Hampel R, Oftedal B, Sørensen M, Wolf K, Aamodt G, Aasvang GM, Aguilera I, Becker T, Beelen R, Brunekreef B, Caracciolo B, Cyrys J, Elosua R, Eriksen KT, Foraster M, Fratiglioni L, Hilding A, Houthuijs D, Korek M, Künzli N, Marrugat J, Nieuwenhuijsen M, Östenson CG, Penell J, Pershagen G, Raaschou-Nielsen O, Swart WJR, Peters A, Hoffmann B (2017) Long-term exposure to ambient air pollution and traffic noise and incident hypertension in seven cohorts of the European study of cohorts for air pollution effects (ESCAPE). Eur Heart J 38(13):983-990

Fyhri A, Aasvang GM (2010) Noise, sleep and poor health: modeling the relationship between road traffic noise and cardiovascular problems. Sci Total Environ 408(21):4935-4942

Georgiadou E, Kourtidis K, Ziomas I (2004) Exploratory traffic noise measurements at five main streets of Thessaloniki, Greece. Global NestI Int J 6(1):53-61

Gidlöf-Gunnarsson A, Öhrström E (2010) Attractive "quiet" courtyards: a potential modifier of urban residents' responses to road traffic noise? Int J Environ Res Public Health 7:3359-3375

Guski R, Schreckenberg D, Schuemer R (2017) WHO environmental noise guidelines for the European region: a systematic review on environmental noise and annoyance. Int J Environ Res Public Health 14(12):1539

Jamir L, Nongkynrih B, Gupta SK (2014) Community noise pollution in urban India: need for public health action. Indian J Community Med 39(1):8-12. https://doi.org/10.4103/0970-0218.126342

Kalawapudi K, Singh T, Dey J, Vijay R, Kumar R (2020) Noise pollution in Mumbai Metropolitan Region (MMR): an emerging environmental threat. Environ Monit Assess 192(2):1-20

Kisku GC, Sharma K, Kidwai MM, Barman SC, Khan AH, Singh R et al (2006) Profile of noise pollution in Lucknow city and its impact on environment. J Environ Biol 37(2):409-412

Mansouri N, Pourmahabadian M, Ghasemkhani M (2006) Road traffic noise in downtown area of Tehran. J Environ Health Sci Eng 3(4): $267-272$
Méline J, Van Hulst A, Thomas F, Karusisi N, Chaix B (2013) Transportation noise and annoyance related to road traffic in the French RECORD study. Int J Health Geogr 12(1):1-13

Miedema HME, Passchier-Vermeer W, Vos H. (2003) TNO Intro report2002-59: elements for a position paper on night-time transportation noise and sleep disturbance. Netherlands, Delft; ToegepastNatuurwetenschappelijkOnderzoek, 2003. Pub. no. 02 5N 16061241.

Miedema HM, Vos H (1998) Exposure-response relationships for transportation noise. J Acoust Soc Am 104(6):3432-3445

Muzet A (2007) Environmental noise, sleep and health. Sleep Med Rev 11(2):135-142

Newman JS, \& Beallie KR (1985) Aviation noise effects, US Department of Transportation. $\mathrm{R}$

Oh M, Shin K, Kim K, Shin J (2019) Influence of noise exposure on cardio cerebrovascular disease in Korea. Sci Total Environ 651: $1867-1876$

Öhrström E, Skånberg A, Svensson H, Gidlöf-Gunnarsson A (2006) Effects of road traffic noise and the benefit of access to quietness. J Sound Vib 295:40-59

Okah-Avae BE (1996) The science of industrial machinery and systems maintenance. Spectrum Books

Ongel A, Sezgin F (2016) Assessing the effects of noise abatement measures on health risks: a case study in Istanbul. Environ Impact Assess Rev 56:180-187

Paiva KM, Cardoso MRA, Zannin PHT (2019) Exposure to road traffic noise: annoyance, perception and associated factors among Brazil's adult population. Sci Total Environ 650:978-986

Pathak V, Tripathi BD, Mishra VK (2008) Dynamics of traffic noise in a tropical city Varanasi and its abatement through vegetation. Environ Monit Assess 146(1-3):67-75

Robinson DW (1971) The concept of noise pollution level. J Occup Environ Med 13(12):602

Saadu AA, Onyeonwu RO, Ayorinde EO, Ogisi FO (1998) Road traffic noise survey and analysis of some major urban centers in Nigeria. Noise Control Eng J 46(4):146-158

Sagar TV, Rao GN (2006) Noise pollution levels in Visakhapatnam city (India). J Environ Sci Eng 48(2):139

Said MA, El-Gohary OA (2016) Effect of noise stress on cardiovascular system in adult male albino rat: implication of stress hormones, endothelial dysfunction and oxidative stress. Gen Physiol Biophys 35(3):371-377

Singh N, Davar SC (2004) Noise pollution-sources, effects and control. J Hum Ecol 16(3):181-187

Stansfeld SA, Matheson MP (2003) Noise pollution: non-auditory effects on health. Br Med Bull 68(1):243-257

Tekalan SA (1991) Effects of noise on hearing and other body systems. Ecol Environ J:2-11

Thakre C, Laxmi V, Vijay R, Killedar DJ, Kumar R (2020) Traffic noise prediction model of an Indian road: an increased scenario of vehicles and honking. Environ Sci Pollut Res 27(30):38311-38320

World Health Organization (2018) Environmental noise guidelines for the European region. Available at: https://www.euro.who.int/en/ publications/abstracts/environmental-noise-guidelines-for-theeuropean-region-2018

van Renterghem T, Botteldooren D (2012) Focused study on the quiet side effect indwellings highly exposed to road traffic noise. Int $\mathrm{J}$ Environ Res Public Health 9:4292-4310

Yilmaz H, Ozer S (2005) Evaluation and analysis of environmental noise pollution in the city of Erzurum, Turkey. Int J Environ Pollut 23(4): $438-448$

Publisher's note Springer Nature remains neutral with regard to jurisdictional claims in published maps and institutional affiliations. 